\title{
Optical properties of lead-tellurite glasses doped with samarium trioxide
}

\author{
B ERAIAH \\ Department of Physics, Bangalore University, Bangalore 560 056, India
}

MS received 1 March 2009; revised 17 April 2010

\begin{abstract}
The optical properties of a new family of $x \mathrm{Sm}_{2} \mathrm{O}_{3}-(40-x) \mathrm{PbO}-60 \mathrm{TeO}_{2}$ glasses are investigated. The optical absorption spectra were recorded at room temperature in the UV-visible region. From the absorption edge studies, the values of optical bandgap energies have been evaluated. The refractive index, molar refraction and polarizability of oxide ions have been calculated by using Lorentz-Lorentz relations. The non-linear variations of the above optical parameters are discussed with respect to samarium concentration.
\end{abstract}

Keywords. Optical bandgap; refractive index; tellurite glasses.

\section{Introduction}

Tellurite glasses are very promising materials for linear and non-linear application in optics, due to some of their important characteristic features such as high refractive index, low phonon maxima and low melting temperature (Vijaya Prakash et al 2001). $\mathrm{TeO}_{2}$ is known as a conditional glass former, as it needs a modifier in order to form the glassy state easily (Halimah et al 2005). Tellurite glasses continue to intrigue both academic and industry researchers not only because of their technical applications, but also owing to a fundamental interest in understanding their microscopic mechanisms. In general, application and utilities of glassy materials are enormous and are governed by the factors like composition, refractive index and dopants present in the glasses.

Moreover, the rare earth in glassy matrix is strongly dependent on crystal field effects, local environment, phonon energies extended into the bandgap (Vijaya Prakash 2000). It has been found that glasses with a high density along with a low dispersion usually have a high non-linear refractive index. The heavy metal oxide glasses containing $\mathrm{PbO}, \mathrm{Bi}_{2} \mathrm{O}_{3}$ and $\mathrm{Ga}_{2} \mathrm{O}_{3}$ are reported (Lapp et al 1989; Daumbaugh and Lapp 1992) to have a high density and refractive index and excellent non-linear properties. There is a major and growing interest in developing photonic and signal processing devices for communications and computing applications (Vogel 1989; Komatsu et al 1991). Optical glasses are considered promising candidates for such devices because they can be made to possess a rapid non-linear response to an optical signal. Optical transparency over a large wavelength

(eraiah@rediffmail.com) range, physical, chemical and thermal properties are suitable for practical applications (Huang et al 1994). The present work intends to study the optical properties of $\mathrm{Sm}_{2} \mathrm{O}_{3}-\mathrm{PbO}-\mathrm{TeO}_{2}$ glasses and to discuss the variations of optical properties with respect to a small concentration of $\mathrm{Sm}_{2} \mathrm{O}_{3}$.

\section{Materials and methods}

Analar grade samarium trioxide $\left(\mathrm{Sm}_{2} \mathrm{O}_{3}\right)$, lead oxide $(\mathrm{PbO})$ and tellurium dioxide $\left(\mathrm{TeO}_{2}\right)$ were used as starting materials for preparation of glass samples. Different compositions of glasses were prepared by using conventional melt quenching method. The detailed experimental method was reported elsewhere (Eraiah 2006). The density of each glass was measured based on the Archimedes method using toluene as an immersion liquid (density = $0.860 \mathrm{~g} / \mathrm{cm}^{3}$ at $R T$ ). The corresponding molar volumes $\left(V_{\mathrm{m}}\right)$ are calculated by using the formula

$$
V_{\mathrm{m}}=M / \rho,
$$

where $M$ is the molecular weight and $\rho$ the density of glass samples. The optical absorption of the polished samples was obtained in the wavelength range 200$800 \mathrm{~nm}$ at room temperature by using Hitachi-U-3200 absorption spectrometer. The optical absorption coefficient $(\alpha(v))$, was calculated for each sample by using the relation

$$
\alpha(v)=A / d,
$$

where $A$ is absorbance and $d$ the thickness of the samples. Optical bandgap energies $\left(E_{\mathrm{g}}\right)$ are calculated by the extrapolation of the linear region to meet $h v$ axis at 
Table 1. Density, molar volume, optical energy bandgap, refractive index, molar refraction and polarizability of oxide ion for $\mathrm{Sm}_{2} \mathrm{O}_{3}-\mathrm{PbO}-\mathrm{TeO}_{2}$ glasses.

\begin{tabular}{|c|c|c|c|c|c|c|c|c|}
\hline \multicolumn{3}{|c|}{ Glass composition (mol\%) } & \multirow{2}{*}{$\begin{array}{l}\text { Density } \\
(\rho)\left(\mathrm{g} / \mathrm{cm}^{3}\right)\end{array}$} & \multirow{2}{*}{$\begin{array}{l}\text { Molar volume } \\
\left(V_{\mathrm{m}}\right)\left(\mathrm{cm}^{-3}\right)\end{array}$} & \multirow{2}{*}{$\begin{array}{c}\text { Energy } \\
\text { bandgap } \\
\left(E_{\mathrm{g}}\right)(\mathrm{eV})\end{array}$} & \multirow{2}{*}{$\begin{array}{l}\text { Refractive } \\
\text { index }(n)\end{array}$} & \multirow{2}{*}{$\begin{array}{l}\text { Molar } \\
\text { refraction } \\
\left(R_{\mathrm{M}}\right)\left(\mathrm{cm}^{3}\right)\end{array}$} & \multirow{2}{*}{$\begin{array}{c}\text { Polarizability } \\
\left(\alpha_{\mathrm{e}}\right) \\
\left(\times 10^{-24}\right)\left(\mathrm{cm}^{3}\right)\end{array}$} \\
\hline $\mathrm{Sm}_{2} \mathrm{O}_{3}$ & $\mathrm{PbO}$ & $\mathrm{TeO}_{2}$ & & & & & & \\
\hline $0 \cdot 0$ & 40 & 60 & $5 \cdot 6027$ & $33 \cdot 0200$ & $2 \cdot 8201$ & $2 \cdot 4409$ & $20 \cdot 6179$ & $8 \cdot 1713$ \\
\hline $0 \cdot 1$ & $39 \cdot 9$ & 60 & $5 \cdot 6102$ & $33 \cdot 0044$ & $3 \cdot 6594$ & $2 \cdot 2444$ & $18 \cdot 9346$ & $3 \cdot 8354$ \\
\hline $0 \cdot 2$ & $39 \cdot 8$ & 60 & $8 \cdot 1301$ & $22 \cdot 7902$ & 3.6943 & $2 \cdot 2318$ & $12 \cdot 9962$ & $2 \cdot 6294$ \\
\hline $0 \cdot 3$ & $39 \cdot 7$ & 60 & $10 \cdot 5778$ & $17 \cdot 5284$ & $3 \cdot 9660$ & $2 \cdot 1764$ & 9.7226 & 1.08266 \\
\hline $0 \cdot 4$ & $39 \cdot 6$ & 60 & $10 \cdot 2894$ & 18.0319 & $3 \cdot 6555$ & $2 \cdot 2399$ & $10 \cdot 3228$ & $1 \cdot 1151$ \\
\hline $0 \cdot 5$ & $39 \cdot 5$ & 60 & $8 \cdot 5500$ & $21 \cdot 7150$ & $4 \cdot 5370$ & $2 \cdot 0735$ & $11 \cdot 3735$ & $2 \cdot 2682$ \\
\hline
\end{tabular}

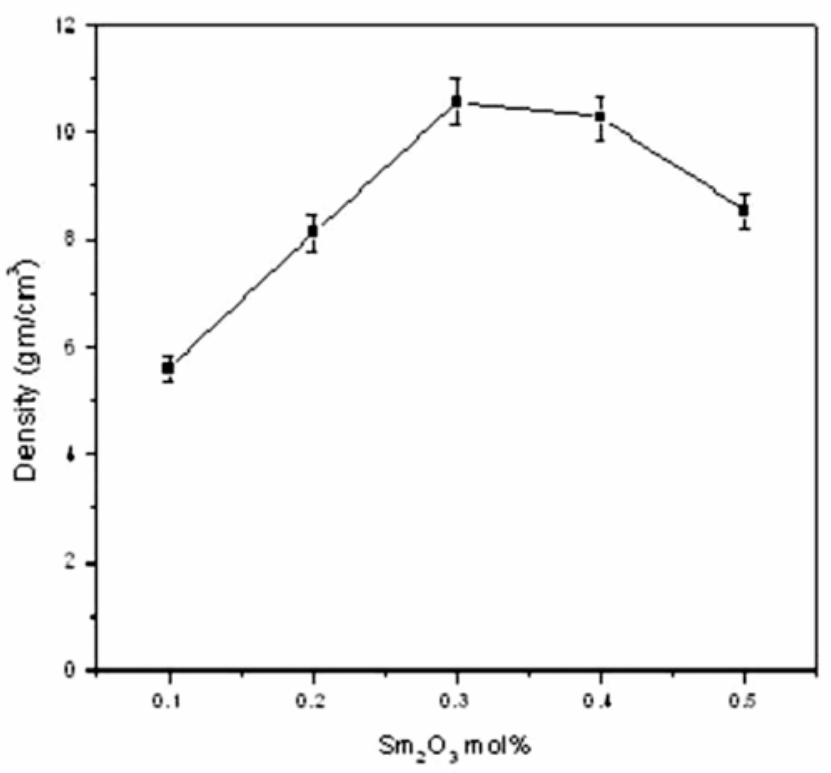

Figure 1. Variation of density as a function of $\mathrm{Sm}_{2} \mathrm{O}_{3}$

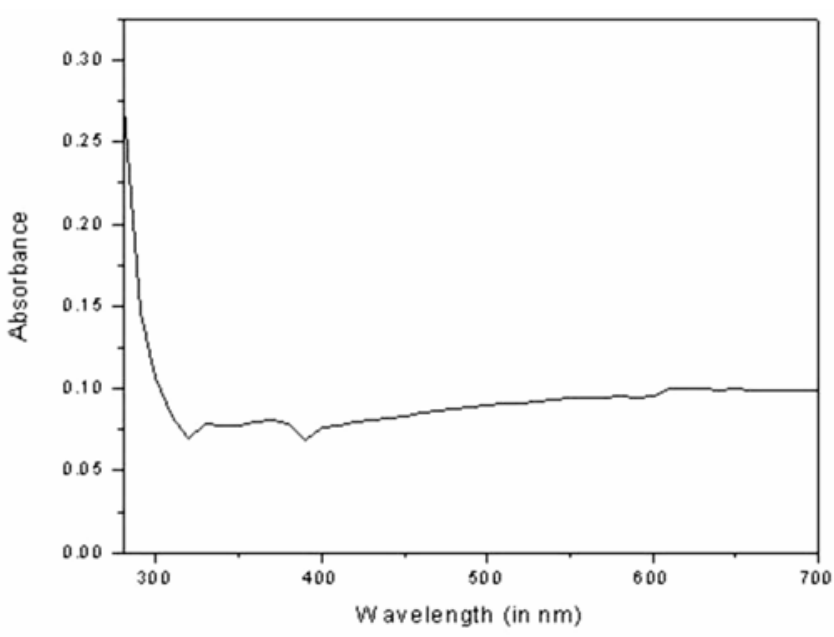

Figure 2. A typical absorption spectrum of $\mathrm{Sm}_{2} \mathrm{O}_{3}-\mathrm{PbO}-$ $\mathrm{TeO}_{2}$ glasses.

$(\alpha h v)^{1 / 2}=0$. Refractive indices of these glasses are calculated by using the relation,

$$
\frac{n^{2}-1}{n^{2}+2}=1-\sqrt{E_{\mathrm{g}} / 20}
$$

which was proposed by Dimitrov and Sakka (1996).

The molar refraction $\left(R_{\mathrm{M}}\right)$ was calculated by using the relation

$$
\frac{n^{2}-1}{n^{2}+2}\left(\frac{M}{\rho}\right)=R_{\mathrm{M}},
$$

and the polarizabilities of these glasses have been estimated by using the Lorentz-Lorentz (Rawson 1980) relation

$$
\frac{n^{2}-1}{n^{2}+2}\left(V_{m}\right)=4 / 3 \pi N \alpha_{\mathrm{e}}
$$

\section{Results and discussion}

The measured and calculated values of densities, molar volumes, energy bandgaps, refractive indices, molar refractions and polarizability of oxide ions of samarium doped lead-tellurite glasses are listed in table 1. The variation of density vs mol\% of $\mathrm{Sm}_{2} \mathrm{O}_{3}$ is shown in figure 1. As can be seen from figure 1 , the density increases up to $0.3 \mathrm{~mol} \%$ and it starts to decrease from $0.4 \mathrm{~mol} \%$. This behaviour may be due to less number of non-bridging oxygen up to $0.3 \mathrm{~mol} \%$ of $\mathrm{Sm}_{2} \mathrm{O}_{3}$, then there is a creation of more number of non-bridging oxygen on increasing the $\mathrm{mol} \%$ of $\mathrm{Sm}_{2} \mathrm{O}_{3}$ and again the density suddenly drops at $0.5 \mathrm{~mol} \%$ of $\mathrm{Sm}_{2} \mathrm{O}_{3}$. The variation of molar volume vs mol\% of $\mathrm{Sm}_{2} \mathrm{O}_{3}$ is exactly opposite to that of density variation is expected. A typical absorption spectrum of $\mathrm{Sm}_{2} \mathrm{O}_{3}-\mathrm{PbO}-\mathrm{TeO}_{2}$ glasses is shown in figure 2 . In amorphous materials the absorption due to the band-to-band transitions that determines the optical energy gap was interpreted by Mott and Davis (1970) and can be written in general form

$$
\alpha(v)=(B / h v)\left(h v-E_{\mathrm{opt}}\right)^{n},
$$

where $B$ is a constant and $h v$ the photon energy, $E_{\text {opt }}$ the optical energy gap and $n$ an index which can have any values between $1 / 2$ and 3 depending on the nature of the 
inter-band electronic transitions (Al-Ani and Higazy 1991). The goodness-of-fit of the data to the formula for either $n=1 / 2$ (direct bandgap) or $n=2$ (indirect bandgap) is determined. The absorption coefficients, $\alpha(v)$, are determined, near the absorption edge at different photon energies for all glass samples. It has been observed that for indirect allowed transitions, the measured absorption data fit well to (4) for $n=2$. Therefore, the results are plotted as $(\alpha h v)^{1 / 2}$ vs photon energy $(h v)$, a typical plot is shown in figure 3, for indirect allowed transitions to find the values of optical bandgap, $E_{\text {opt }}$. It can be seen that there exists a linear dependence of $(\alpha h v)^{1 / 2}$ in the photon energy $(h v)$. This suggests that at higher photon energies the transitions occurring in the present glass samples are of indirect type. The variation of optical energy bandgap

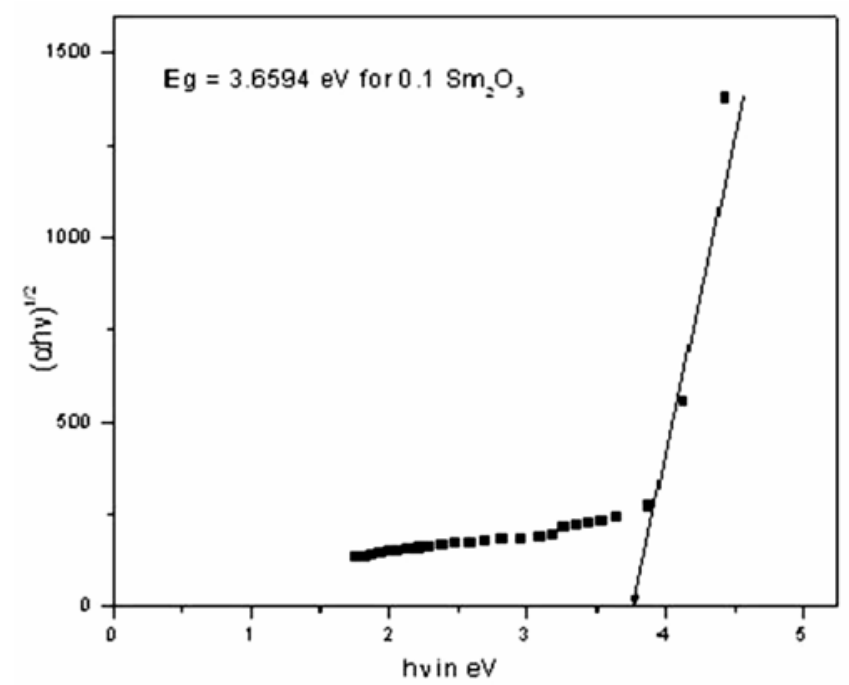

Figure 3. A typical plot of $(\alpha h v)^{1 / 2}$ vs photon energy $(h v)$.

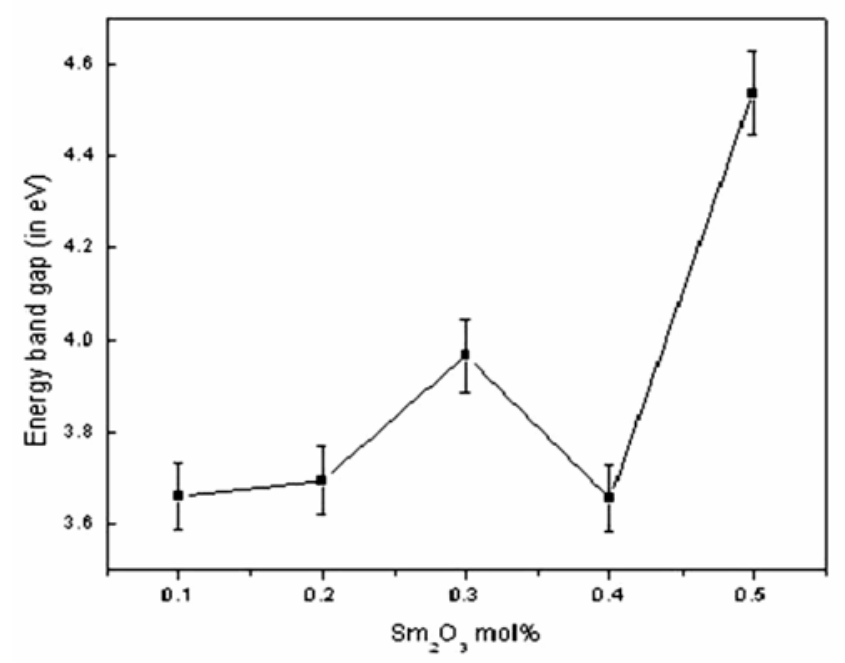

Figure 4. Variation of optical energy bandgap values vs $\mathrm{mol} \%$ of $\mathrm{Sm}_{2} \mathrm{O}_{3}$. values vs $\mathrm{mol} \%$ of $\mathrm{Sm}_{2} \mathrm{O}_{3}$ is shown in figure 4 . The $E_{\mathrm{g}}$ values increase linearly with increase of $\mathrm{Sm}_{2} \mathrm{O}_{3}$ up to $0.3 \mathrm{~mol} \%$ and suddenly drops at $0.4 \mathrm{~mol} \%$ and again it increases at $0.5 \mathrm{~mol} \%$ of $\mathrm{Sm}_{2} \mathrm{O}_{3}$. This may be due to the creation of more non-bridging oxygen at $0.4 \mathrm{~mol} \%$ of $\mathrm{Sm}_{2} \mathrm{O}_{3}$ and hence a glass structure change takes place. This also may be due to the presence of higher valence oxide ion, $\mathrm{Pb}^{2+}$, when it is acting as a modifier, the cations present in the network can produce important structural effects. There are reports in the literature which suggest that $\mathrm{Zn}^{2+}, \mathrm{Mg}^{2+}, \mathrm{Pb}^{2+}$ etc occupy both network and non-network positions (Kim and Bray 1974; Ganguli and Rao 1999; Ganguli et al 1999). More probably, PbO ionizes as $\mathrm{Pb}^{2+}$ and $\mathrm{O}^{2-}$ and results in modifying the network. At $0.4 \mathrm{~mol} \% \mathrm{Sm}_{2} \mathrm{O}_{3}$, part of $\mathrm{Pb}$ is likely to behave as a network former. Due to this reason energy bandgap variation takes place at $0.4 \mathrm{~mol} \%$ of $\mathrm{Sm}_{2} \mathrm{O}_{3}$. Figure 5 shows the variation of refractive indices vs $\mathrm{mol} \%$ of $\mathrm{Sm}_{2} \mathrm{O}_{3}$, the trend in variation is exactly opposite to the energy bandgap variation as expected. In these glasses the glass-forming network is formed by $\mathrm{O}-\mathrm{Pb}-\mathrm{O}$ linkages with $\left[\mathrm{PbO}_{6}\right]$ octahedral and $\left[\mathrm{PbO}_{4}\right]$ tetrahedral (Nachimuthu and Jagannathan 1995). The $s$ and $p$ orbitals of $\mathrm{Pb}^{2+}$ and $p$ orbital of oxygen interact with each other to form bonding and antibonding states which give rise to valence bond and conduction bond, respectively. The number of strong $\mathrm{O}-\mathrm{Pb}-\mathrm{O}$ linkages increases resulting in the narrowing of the bandgap energies (Vithal et al 1997) which can account for the increase of refractive index at the composition, $0 \cdot 4$, as well as decrease for the compositions corresponding to 0.3 and $0.5 \mathrm{~mol}^{\%}$ of $\mathrm{Sm}_{2} \mathrm{O}_{3}$. Figure 6 shows the variation of polarizability of oxide ions vs $\mathrm{mol} \%$ of $\mathrm{Sm}_{2} \mathrm{O}_{3}$. As can be seen from figure 6 the polarizability decreases gradually up to $0.3 \mathrm{~mol} \%$ of $\mathrm{Sm}_{2} \mathrm{O}_{3}$ then increases suddenly from $0.4 \mathrm{~mol} \%$ to $0.5 \mathrm{~mol} \%$

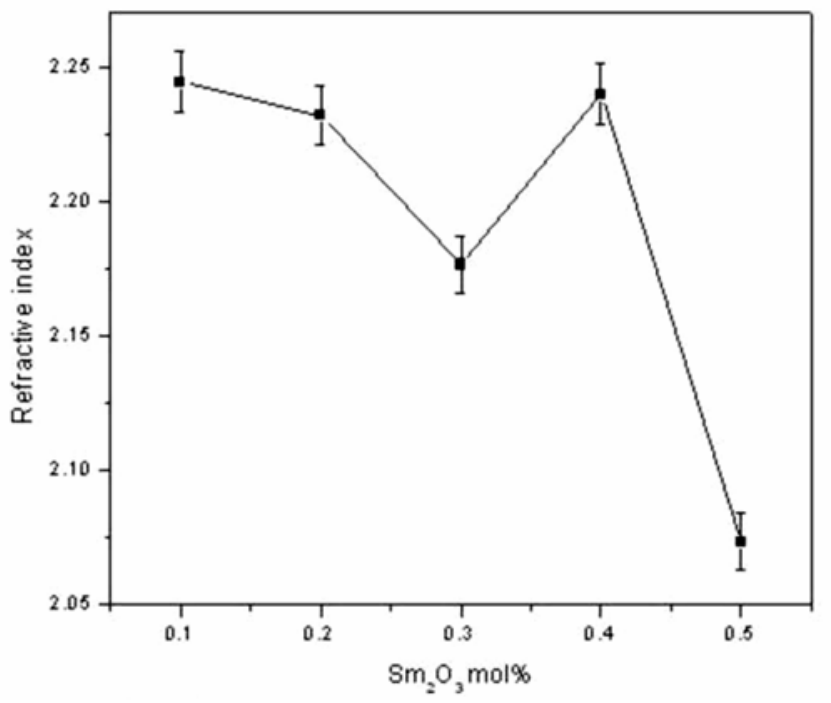

Figure 5. Variation of refractive indices vs mol\% of $\mathrm{Sm}_{2} \mathrm{O}_{3}$. 


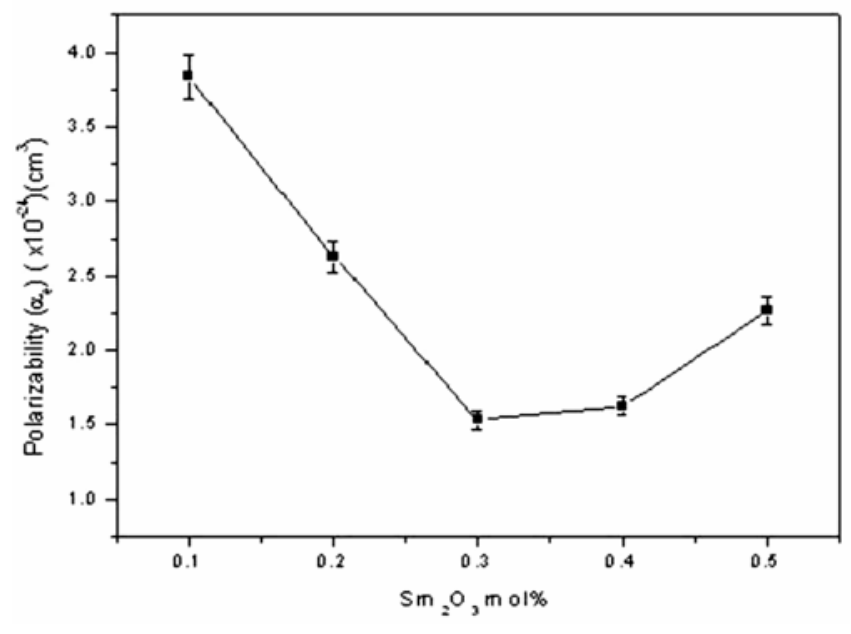

Figure 6. Variation of polarizability of oxide ions vs mol\% of $\mathrm{Sm}_{2} \mathrm{O}_{3}$.

of $\mathrm{Sm}_{2} \mathrm{O}_{3}$. This may be due to breaking of $\mathrm{Te}-\mathrm{O}-\mathrm{Te}$ bonds when $\mathrm{Pb}$ enters into network position and formed new non-bridging bonds like $\mathrm{Te}-\mathrm{O}-\mathrm{Pb}^{2+}$. Also a substitution of cations into $\mathrm{TeO}_{2}$ network induces a structural variation from $\left(\mathrm{TeO}_{4}\right)^{4-}$ to $\left(\mathrm{TeO}_{3}\right)^{2-}$ entities through an intermediate asymmetric structure (Neov et al 1979). This leads to a significant change in the optical properties.

\section{Conclusions}

$\mathrm{Sm}_{2} \mathrm{O}_{3}-\mathrm{PbO}-\mathrm{TeO}_{2}$ glasses have been prepared and their optical properties are investigated. Densities and energy bandgaps are discussed in terms of the glass composition and structure. In both the cases the variation with respect to samarium concentration is found to be similar at $0.4 \mathrm{~mol} \%$ of $\mathrm{Sm}_{2} \mathrm{O}_{3}$. This variation is also reflected in refractive indices and polarizability of oxide ions. In these glasses the variation at $0.4 \mathrm{~mol} \% \mathrm{Sm}_{2} \mathrm{O}_{3}$ was not only due to the presence of $\mathrm{Sm}^{2+}$ ions, but also due to the dual role of $\mathrm{Pb}^{2+}$ ions, which are responsible for significant change in the optical properties of these glasses.

\section{References}

Al-Ani S K J and Higazy A A 1991 J. Mater. Sci. 263670 Daumbaugh W H and Lapp J C 1992 J. Am. Ceram. Soc. 75 2315

Dimitrov V and Sakka S 1996 J. Appl. Phys. 791736

Eraiah B 2006 Bull. Mater. Sci. 29375

Ganguly M and Rao K J 1999 J. Solid State Chem. 14565

Ganguly M, Harish Bhat M and Rao K J 1999 Phys. Chem. Glasses 40297

Halimah M K, Daud W M, Sidek H A A, Zainal A T, Zainal H and Jumaiah Hassan 2005 Am. J. Appl. Sci. 63

Huang W H, Ray C S and Day D E 1994 J. Am. Ceram. Soc. 77 1017

Kim K S and Bray P J 1974 Phys. Chem. Glasses 1547

Komatsu T, Tawarayama H, Mohro H and Mutusita K $1991 \mathrm{~J}$. Non-Cryst. Solids 135105

Lapp J C, Daumbaugh W H and Powley M L 1989 Rev. Stn. Sper vetro 1991

Mott N F and Davis E A 1970 Philos. Mag. 28903

Nachimuthu P and Jagannathan R 1995 J. Appl. Phys. 787323

Neov S, Kozhukharov V, Gerasimova I, Kurzhov K and Sidzhimov B 1979 J. Phys. C: Solid State Phys. 122475

Rawson H 1980 Properties and applications of glass (Amsterdam: Elservier)

Vijaya Prakash G 2000 Mater. Lett. 4615

Vijaya Prakash G, Narayan Rao D and Bhatnagar A K 2001 Solid State Commun. 1193944

Vithal M, Nachimuthu P, Banu T and Jagannathan R 1997 J. Appl. Phys. 817922

Vogel E M 1989 J. Am. Ceram. Soc. 72719 